\title{
PERSPECTIVAS DE FORMAÇÃO INTEGRADA NOS CURSOS TÉCNICOS DO IFMT - CAMPUS RONDONÓPOLIS
}

\author{
Rudinei Itamar Tamiosso Wesz ${ }^{1}$ \\ Sandra Valéria Limonta Rosa²
}

\section{Resumo}

Este texto resulta da dissertação de Mestrado do Programa de Pós-Graduação em Educação da Faculdade de Educação da Universidade Federal de Goiás/PPGE/ FE/UFG, do convênio MINTER em Educação UFG/IFMT, que teve como objetivo principal identificar e analisar as perspectivas de formaçáo integrada nesta instituição. A pesquisa foi feita em três cursos integrados desta instituição: Técnico em Alimentos Integrado ao Nível Médio, Técnico em Química Integrado ao Nível Médio e o curso Técnico em Secretariado Integrado ao Nível Médio. A pesquisa compreende uma abordagem qualitativa do tipo bibliográfica e documental. O método adotado é o materialismo histórico-dialético, fundamentado no pensamento de Marx, que possibilita teoricamente entender a realidade educacional, visto que a dialética marxista contrapóe-se à lógica formal que se tornou insuficiente para compreender esse processo. $\mathrm{O}$ estudo aponta para a importância da educação profissional baseada na concepção de formação humana omnilateral emancipadora e do trabalho como princípio educativo. A educaçáo profissional ancorada nesses sentidos possibilita a formação emancipatória, na qual os sujeitos serão capazes de compreender a realidade social, econômica, política, cultural, podendo contribuir e agir de acordo com os interesses coletivos visando a uma sociedade mais justa.

Palavras-chave: Educação profissional. Formação integrada. Politecnia.

1 Mestre, professor do Instituto Federal de Educação, Ciência e Tecnologia, campus Rondonópolis. E-mail: rudinei.wesz@roo.ifmt.edu.br

2 Pós-doutora, professora associada da Universidade Federal de Goiás na Faculdade de Educação. E-mail: sandralimonta@gmail.com 


\section{Introdução}

Este texto é um recorte dos estudos do curso de Mestrado em Educação pelo Programa de Pós-Graduação em Educação da Faculdade de Educação da Universidade Federal de Goiás/PPGE/FE/UFG, do convênio MINTER em Educação UFG/IFMT, cujo tema é "Perspectivas de formação integrada nos cursos técnicos do IFMT - Campus Rondonópolis".

O problema da pesquisa está amparado pela proposta de integraçáo do curso médio e do curso técnico de nível médio, segundo o Decreto n. 5.154/04, no qual o currículo deve garantir a efetiva formaçáo integral e ommilateral dos sujeitos, a partir da articulação entre formação geral e profissional, da articulação entre formação técnica e política, da formação ética e do compromisso social.

E, em contrapartida, as forças capitalistas representadas pelos interesses empresariais somam esforços para derrubar essas propostas, aceitando a formação integrada e politécnica somente em termos formais. Pergunta-se: Quais as atuais perspectivas para a real implementaçáo da formação integrada e politécnica nos cursos técnicos integrados ao ensino médio do Instituto Federal de Educação, Ciência e Tecnologia de Mato Grosso, Campus Rondonópolis?

O objetivo geral da pesquisa é identificar e analisar as perspectivas de formação integrada dos cursos técnicos integrados do IFMT, Campus Rondonópolis-MT, bem como as reais possibilidades de implementaçáo desse tipo de formação na instituição. Como objetivos específicos a pesquisa pretende analisar os documentos legais que norteiam a proposta de formaçáo integrada no IFMT buscando compreender como se apresentam os conceitos de formaçáo integrada e formação politécnica, que orientam o trabalho a ser realizado no instituto.

Propomo-nos, entáo, a realizar um estudo bibliográfico sobre educação profissional na perspectiva da formaçáo integrada dentro da concepção de escola unitária e da educação politécnica como direito social universal. Analisaremos os referenciais bibliográficos que norteiam o pensamento clássico e atual sobre os seguintes objetos de estudo: educaçáo profissional, formação integrada, currículo integrado, bem como a análise de documentos que norteiam este tipo de formação.

Serão analisadas as leis que normatizaram a educação profissional, os documentos oficiais referentes ao histórico dos IFs, os programas institucio- 
nais nos quais são apresentadas as propostas educacionais da instituição e os documentos que orientam os cursos analisados.

A pesquisa compreende uma abordagem qualitativa do tipo bibliográfica e documental, o método de pesquisa adotado é o materialismo histórico-dialético fundamentado no pensamento de Marx, nos possibilita teoricamente entender a realidade educacional, visto que a dialética marxista contrapóe-se à lógica formal (separação do sujeito-objeto) que se tornou insuficiente para compreender esse processo.

Nesse sentido, compreender o processo educacional em sua concretude significa refletir sobre as "[...] contradiçóes da organização do trabalho em nossa sociedade, sobre as possibilidades de superação de suas condiçóes adversas" e empreender ações no interior do processo educativo que "[...] contribuam para a humanização plena do conjunto dos homens em sociedade" (PIRES, 1997, p. 91).

A concepção dicotômica de ensino médio brasileiro, propedêutico $\mathrm{x}$ profissional, possui raízes históricas relacionadas à divisão social do trabalho. Apesar de esforços recentes para diminuir essa ambiguidade com a criação do ensino médio integrado, o sistema de ensino atual encontra-se arraigado na "teoria das competências", e conforme essa visão o ensino médio brasileiro permanece tradicionalmente indefinido entre o ensino regular e o profissional.

Moura (2013c, p. 705) defende que, apesar de ser utópica na realidade socioeconômica e educacional brasileira, a construçáo de uma sociedade justa dependeria da formação "[...] omnilateral, integral ou politécnica de todos, de forma pública e igualitária e sob a responsabilidade do estado”. Evidente que essa tarefa não é fácil, no entanto, segundo o autor, é necessária, pois ela dá “[...] sentido ao pensamento e à ação de intelectuais orgânicos, de alguns políticos e partidos, de alguns líderes sindicais e comunitários” possibilitando a edificação de uma sociedade justa ou no mínimo "[...] menos injusta do que a atual" (MOURA, 2013b, p. 130).

$\mathrm{Na}$ década de 1980 ocorreram intensos debates no sentido de reestruturar o sistema educacional brasileiro instituído durante o regime militar. Dermeval Saviani foi um dos precursores no Brasil a discutir conceitos que envolviam as concepções de omnilateralidade e formação politécnica, consubstanciando sobremaneira a concepção marxista de educação.

O seu texto Sobre a concepção de politecnia (SAVIANI, 1989), apresentado no Seminário Choque Teórico, torna-se um marco nas discussóes sobre 
a área trabalho e educação, principalmente no que tange às relações entre o ensino médio e a educação profissional, visto que apresenta em seus escritos a teoria da formação humana segundo as concepções de homem, sociedade e educação baseados nos ideários de Marx e Gramsci.

Mesmo com a chamada Reforma da Educação Profissional, instituída pela promulgação do Decreto no 2.208/97, a dimensão socialista da relação entre o ensino médio e a educação profissional permaneceu incipiente, posto que o referido decreto estabeleceu de forma evidente a dualidade estrutural do ensino brasileiro.

Em 2004, o Decreto no 5.154/04 é publicado após longos debates com vários setores da sociedade e audiências públicas, visando à regulamentação transitória dos artigos da LDB (Lei no 9.394, de 1996), referentes ao ensino médio e à educação profissional, bem como a revogação do Decreto no 2.208/97 e de trazer de volta a possibilidade de integrar o ensino médio à educação profissional técnica de nível médio, agora, numa perspectiva que, apesar de não se caracterizar totalmente como educação tecnológica ou politécnica, aponta em sua direção porque contém os princípios de sua construção.

A politecnia, cujo princípio educativo é o trabalho no sentido ontológico da existência humana, segundo as concepçóes marxianas, contrapóe-se à formação prescrita pela lógica do sistema capitalista. Gramsci, em seus estudos, indica o projeto da escola unitária como forma de transformaçáo social, tendo como princípio desta escola a "filosofia da práxis" princípio propiciará a elevação cultural e política das massas.

Neste sentido Gramsci afirma que o “[...] advento da escola unitária significa o início de novas relaçóes entre trabalho intelectual e trabalho industrial não apenas na escola, mas em toda a vida social”. Dessa forma o princípio unitário “[...] irá se refletir em todos os organismos de cultura, transformando-os e emprestando-lhes um novo conteúdo" (GRAMSCI, 1982, p. 125).

Quanto à discussão sobre as políticas para a educação profissional e tecnológica (EPT) ela vem ocorrendo desde os anos 1980 entre pesquisadores e defensores da formação politécnica no Brasil: Gaudêncio Frigotto, Acácia Kuenzer, Dermeval Saviani, Marise Nogueira, Maria Ciavatta, Dante Henrique Moura, Ramon de Oliveira, Paolo Nosella, entre outros.

3 Para Gramsci, a "filosofia da práxis" é uma expressão autônoma que define, em seu entendimento, o que é uma característica central do legado de Marx: o vínculo inseparável entre a teoria e a prática, o pensamento e a ação (MONASTA, 2010, p. 31). 


\section{Educação profissional integrada ao ensino médio: história, política e concepções}

Conforme Kuenzer (2007), a formação do trabalhador brasileiro remete à histórica dualidade estrutural da educação brasileira, tendo em vista que sempre houve uma nítida trajetória educacional para a elite e outra para o operário. Observa-se desde sempre o cunho dicotômico do ensino médio, um ramo seria orientado aos estudos clássicos, destinados ao ensino superior, e outro ramo seria uma mescla de estudos propedêuticos com estudos profissionais voltados à indústria, à agricultura e ao comércio.

O ensino profissional apregoado pelas Escolas de Aprendizes e Artífices, criadas em 1909, foi concretizando-se ao longo dos anos e adquirindo os contornos necessários até se constituir na rede de Escolas Técnicas, atualmente, os Institutos Federais de Educação, Ciência e Tecnologia existentes no país.

Várias reformas educacionais ocorreram ao longo da história da educação brasileira, nos ateremos às de maiores significações para a educação profissional. Segundo Frigotto e Ciavatta (2003), o governo de FHC, período em que se implementou o Decreto n. 2.208/1997, foi uma época de mediocridade e retrocesso, tanto no âmbito econômico e político como no social, cultural e educacional pelo fato de o governo ter conduzido as diferentes políticas subordinadas aos organismos internacionais, pautadas pela doutrina neoliberal.

No governo Lula, o Decreto n. 2.208/1997 foi revogado e após intensos debates foi aprovado o Decreto n. 5.104/2004, que traz de volta a possibilidade de integrar o ensino médio à educação profissional técnica de nível médio, agora, numa perspectiva que, apesar de não se caracterizar totalmente como educação tecnológica ou politécnica, aponta em sua direção porque contém os princípios de sua construção.

Se por um lado o novo decreto possibilitou a integração do ensino médio com a educaçáo profissional mediante a oferta do ensino médio integrado ao ensino técnico, por outro lado, manteve as alternativas anteriores que expressavam a histórica dualidade do ensino brasileiro:

[...] traz dentro de si as mesmas contradiçôes, deixando claro que a definição e conduçâo da política educacional dependerão fundamentalmente da ação das instituições da sociedade civil organizada que tenham compromisso com a construção e o avanço 
da democracia social e da capacidade de interlocução e pressão destes com os governos (GARCIA; LIMA FILHO, 2004, p. 25).

Com a revogação do antigo decreto, e a substituição pelo Decreto n. 5.154/2004 abriu-se a possibilidade da oferta de educação profissional técnica de nível médio com o respectivo ensino médio de forma integrada, em um mesmo curso, com currículo adequado e articulado a uma proposta de formação integrada, abrindo uma chance para que os princípios da educaçáo socialista - formaçáo omnilateral, politécnica e de base unitária - se efetivassem como política pública, retomando-se a discussão sobre a educação politécnica. No entanto manteve as outras duas possibilidades de articulação previstas no Decreto n. 2.208/1997 - as formas subsequentes e concomitantes.

A luta permanente pelo ensino médio como formação básica, dentro da concepção de escola unitária e da educação politécnica como direito social universal, dando condiçóes de superar a formação profissional como adestramento e adaptação às demandas do mercado de capital, capacitando o trabalhador a lutar por sua emancipação, são propostas dos educadores Ciavatta, Frigotto e Ramos (2012b, p. 15), que dessa forma defendem:

[...] um ensino médio de quatro anos que, de forma articulada e integrada a uma formação científico-tecnológica e ao conhecimento histórico social, permita ao jovem a compreensão dos fundamentos técnicos, sociais, culturais e políticos do atual sistema produtivo. Isso não elide que, dentro do processo de travessia, busque aprofundar-se em determinada área técnica. Cabe, contudo, ao processo educativo, desmistificar o senso comum que isso lhe garante o acesso ao mercado de trabalho. A luta pelo direito ao trabalho dá-se no campo mais amplo da sociedade. Permitir entender isso é a tarefa de um processo educativo emancipatório.

Nesse sentido, conceitualmente, a concepção de educação profissional integrada ao ensino médio significa muito mais que a articulaçáo entre educação geral e educação profissional. Ela está associada também à luta pela superação do dualismo estrutural da educação, a divisão de classes sociais, 
da segmentação entre formação para o trabalho manual ou formação para o trabalho intelectual, buscando:

\begin{abstract}
[...] recuperar, no atual contexto histórico e sob uma específica correlação de forças entre as classes, a concepção de educação politécnica, de educação omnilateral e de escola unitária, que esteve em discussão por uma nova LDB iniciada nos anos 1980 e que se perdeu com a aprovação da Lei no 9.394/1996 (CIAVATTA; RAMOS, 2012, p. 308).
\end{abstract}

Na concepção de Ciavatta e Ramos (2012, p. 308), - integrar - não se trata de integrar um a outro na forma, ou seja, juntar o ensino médio à educação profissional, mas sim constituir o ensino médio como "[...] um processo formativo que integre as dimensóes estruturantes da vida, trabalho, ciência e cultura”, abrindo novas perspectivas de vida para os jovens visando à superação das desigualdades entre as classes sociais, possibilitando ao educando a "[...] compreensão das partes no seu todo ou da unidade no diverso".

A formação integrada ou a educação integrada à educação profissional, tendo em vista que a formação profissional é uma imposição da realidade da população trabalhadora, deveria ser garantida de forma que se desenvolvesse sobre uma base unitária de formação geral, sendo uma "[...] condição necessária para se fazer a travessia para a educação politécnica e omnilateral" (CIAVATTA; RAMOS, 2012, p. 309), incorporando o trabalho como princípio educativo e como "[...] contexto econômico, formando uma unidade com a ciência e a cultura”, na perspectiva da formação humana integral.

\title{
2 Educação profissional na perspectiva da formação humana
}

Segundo as reformas educativas, iniciadas na década de 1990, a ideia básica presente é de que os sistemas educacionais deveriam ser mais flexíveis e diversificados com o objetivo de maior competitividade e redução de custos. Essas reformas, em acordo com as recomendaçóes do Banco Mundial para os países da América Latina, fundamentam-se na lógica do mercado. A educação passa a ser tratada náo mais como direito social, mas como um serviço mercadológico, os demais atores do processo são considerados prestadores de serviço - professores - e clientes - alunos. 
Contrapondo-se a essas ideias, educadores como Dante Henrique Moura, Gaudêncio Frigotto, Maria Ciavatta, Marise Nogueira Ramos, Paolo Nosella, Mario Alighiero Manacorda, dentre outros, vêm discutindo a importância de uma formação integrada para o trabalhador que supere as imposiçóes da formação fragmentada e aligeirada segundo as exigências do mercado de trabalho.

Com vistas à superação de dicotomias antigas do sistema educacional brasileiro, uma das possibilidades foi a concepção dos cursos de educação profissional com a organizaçáo curricular integrada ao ensino médio, com a intenção de articular-se a teoria com a prática, considerando-se a importância das relaçóes entre os saberes científicos e os saberes experienciados, procurando-se superar a dualidade estrutural entre formação propedêutica e formação profissional.

Segundo Garcia e Lima Filho (2004, p. 29), esta concepção contrapõe-se às visôes "[...] utilitaristas - pelas quais o jovem educando é reduzido à mera condição de capital humano" a ser capacitado para as demandas do mercado - e à educação como uma "condição mercantil". Os autores entendem a educação profissional integrada à educação básica, como um processo "formativo integral", que busca a compreensão da problemática social do educando como "sujeito de direitos e de ações na sociedade" buscando contribuir com a inserção desses sujeitos como cidadãos autônomos no mundo do trabalho.

A educação profissional integrada ao ensino médio tem como base teórica de referência a formação omnilateral, inspirada nas ideias de Marx. Tem como objetivos a formação integral para o trabalho e para a cidadania, norteada pelo projeto socialista de formação politécnica ou tecnológica de base unitária. Este projeto compreende a educação na perspectiva da formação humana, que se opóe ao histórico projeto pensado pelo capital.

Para entendermos a concepção de escola unitária, utilizaremos os escritos de Antonio Gramsci, bem como as interpretaçôes e estudos feitos sobre a obra gramsciana realizados por Mario Alighiero Manacorda, tendo em vista que este autor é considerado um clássico entre os pesquisadores da educaçáo no que se refere aos pensamentos gramscianos e também nos textos do igualmente italiano naturalizado brasileiro Paolo Nosella, entre outros.

A proposta de uma escola unitária segundo os ideários de Gramsci surgiu no final do século XIX, na Europa, em meio a vários movimentos organizados 
pelo proletariado em um contexto de profundas transformaçóes no modo de reprodução capitalista. Nesse contexto, Gramsci revela a dicotomia entre a educaçáo cultural e instruçáo para o trabalho e suas preocupaçóes com a educação e a escola, pois ele acreditava que o mundo pode ser transformado e que a educação e a cultura podem "[...] ser causa e efeito dessa mudança, enquanto espaços de formação, informação, reflexão e construção do consenso na sociedade [...] além do que a escolarização é um meio de formação massiva de quadros dirigentes e de cidadáos em geral" (NOSELLA; AZEVEDO, 2012, p. 25, 26).

Gramsci é um seguidor original das propostas de Marx principalmente no que tange à educação e à escola. Para Marx a educação necessária para a classe trabalhadora consistiria no seguinte:

1) Educação intelectual. 2) Educação corporal, tal como a que se consegue com os exercícios de ginástica e militares. 3) Educação tecnológica, que recolhe os princípios gerais e de caráter científico de todo o processo de produção e, ao mesmo tempo, inicia as crianças e os adolescentes no manejo de ferramentas elementares dos diversos ramos industriais. [...] Esta combinação de trabalho produtivo pago com a educação intelectual, os exercícios corporais e a formação politécnica elevará a classe operária acima dos níveis das classes burguesa e aristocrática (MARX; ENGELS, 2011, p. 85, 86).

Nesta perspectiva, a combinação das duas dimensóes do processo de trabalho produtivo (a intelectual e a prática), dando oportunidade do conhecimento do processo fabril de produção como um todo, ausente na educaçáo da burguesia, permitiria elevar a classe trabalhadora acima da classe burguesa, contribuindo com a emancipaçáo do trabalhador.

É imperativo ressaltar que a proposta gramsciana de uma escola unitária, vinculada à tese do trabalho como princípio educativo, fora vinculada por Gramsci em um contexto histórico em que se ampliavam horizontes para a construçáo de uma sociedade socialista. A teoria de Gramsci incorpora as categorias marxistas nas lutas e consciência de classes no processo de transformação de uma sociedade movida pelo capital.

Deve-se entender a escola "única", proposta por Gramsci naquele momento histórico, como sinônimo de uma escola comum a todos, ou seja, 
com oportunidade de acesso para todos os indivíduos, uma vez que o ensino técnico italiano de caráter pragmático era destinado às classes subalternas e o ensino humanista, intelectual, destinado às classes privilegiadas. Entende-se também por "única" no sentido de "[...] confluir e solidificar-se o trabalho das academias e das universidades com as necessidades de cultura científica das massas nacionais-populares, reunindo a teoria e a prática, o trabalho intelectual e o trabalho industrial” (GRAMSCI, 1982, p. 155).

Nesse contexto, Gramsci defende uma escola "desinteressada”, " humanística” também para o proletariado, reconhecendo, entretanto, a necessidade de formar homens "completos" no sentido de buscar uma "[...] relação positiva entre a educação e a instrução, entre a escola humanística e a escola profissional", pois Gramsci já percebia naquela época a crise do programa da organização escolar onde "a divisão fundamental da escola em clássica e profissional era um esquema racional: a escola profissional destinava-se às classes instrumentais, ao passo que a clássica destinava-se às classes dominantes e aos intelectuais" (GRAMSCI, 1982, p. 118). Nessa perspectiva, Gramsci faz críticas à escola limitadora do desenvolvimento que cria "mamíferos de luxo" ou "homens pela metade":

A escola profissional não deve se tornar uma incubadora de pequenos monstros aridamente instruídos para um ofício, sem ideias gerais, sem cultura geral, sem alma, mas só com o olho certeiro e a mão firme [...] É também através da cultura profissional que se pode fazer com que do menino brote o homem, desde que essa seja uma cultura educativa e não apenas informativa (MANACORDA, 2013, p. 36).

Manacorda (2007, p. 136) afirma que a premissa teórica, integralmente marxiana e adotada por Gramsci é de uma “[...] escola única inicial de cultura geral, humanística, formativa que harmonize precisamente o desenvolvimento da capacidade de trabalho intelectual", pois para Gramsci o trabalho é um elemento essencialmente constitutivo do ensino e o destaca como "[...] princípio educativo imanente da escola elementar”.

Sobre a concepção de politecnia, Saviani (2003) argumenta que "[...] a noção de politecnia se encaminha na direção da superação da dicotomia entre trabalho manual e trabalho intelectual, entre instrução profissional e 
instrução geral” (p. 136), e que a politecnia “[...] diz respeito ao domínio dos fundamentos científicos das diferentes técnicas que caracterizam o processo de trabalho produtivo moderno (p. 140).

A proposta de ensino médio unitário tendo o trabalho como princípio educativo implica a "[...] compreensão do significado econômico, social, histórico, político e cultural das ciências e das artes" (MOURA, 2010, p. 8), levando ao entendimento de sua dimensão ontológica e histórica. A dimensão ontológica, ainda segundo o autor, é entendida “[...] como práxis humana e, então, como a forma pela qual o homem produz sua própria existência na relação coma natureza e com os outros homens e, assim, produz conhecimentos" e é assumida quando se compreende que as condiçóes naturais de existência são transformadas visando suprir suas necessidades de sobrevivência resultando em conhecimentos que permitem ao homem agir e transformar a natureza e a si mesmo.

Para educar o homem do futuro será necessário, de acordo com Nosella (2016, p. 46), “[...] ultrapassar os limites burgueses do trabalho alienado". O autor defende ainda que o processo educativo precisa inverter a constituiçáo histórica do trabalho como manifestação de si que se tornou perdição de si, recuperando na medida do possível o significado social e o sentido individual de que o trabalho é liberdade e criação.

Ainda segundo o autor, o trabalho como princípio educativo foi um conceito elaborado e proposto com base no processo de industrialização, no momento em que os homens entenderam que os conhecimentos necessários para o desenvolvimento da indústria eram resultados da articulação entre as atividades práticas e teóricas, uma vez que eram realizadas operaçóes segundo regras objetivas teóricas e práticas, dessa forma o trabalho passou a significar o processo educativo.

Assim, o trabalho como princípio educativo passou a significar o objetivo geral de todo o processo educativo, isto é, capacitar as gerações mais novas para transformar a natureza, de forma científica, humanizando-a. Destarte, à instituição escolar competia desenvolver atividades didáticas específicas e próprias de cada fase etária visando alcançar o objetivo geral (NOSELLA, 2016, p. 59). 
Nesta mesma perspectiva ontológica e histórica da educação e do trabalho, Frigotto, Ciavatta e Ramos (2005) apontam a primeira como atividade criativa e fundamental da vida produzindo conhecimentos na medida da compreensão dos processos históricos de produção científica e tecnológica, portanto - práxis humana e a segunda como forma histórica produzida socialmente nas relaçóes do mundo do capital "[...] na medida em que coloca exigências específicas para o processo educativo, visando à participação direta dos membros da sociedade no trabalho socialmente produtivo" (p. 36).

A partir da percepção e constatação do trabalho como práxis, possibilitando a criação e recriação do mundo humano, não apenas no plano econômico, mas no âmbito da arte e da cultura, linguagens e símbolos, em resposta às suas históricas e múltiplas necessidades, o trabalho se engendra como princípio educativo ou formativo, não sendo apenas mais uma técnica didática ou metodológica no processo da aprendizagem, mas um princípio ético-político.

O trabalho como princípio educativo deriva do fato de que todos os seres humanos são seres da natureza e, portanto, têm a necessidade de alimentar-se, proteger-se das intempéries e criar seus meios de vida. É fundamental socializar, desde a infância, o princípio de que a tarefa de prover a subsistência, e outras esferas da vida do trabalho, é comum a todos os seres humanos, evitando-se, desta forma, criar indivíduos ou grupos que exploram e vivem do trabalho de outros. Estes, na expressão de Gramsci, podem ser considerados mamíferos de luxo - seres de outra espécie que acham natural explorar outros seres humanos (FRIGOTTO, 2012, p. 60).

A partir do exposto ampliam-se as percepçóes de educação profissional na perspectiva da formação humana. Ciavatta (2012, p. 85) afirma que o que se busca como formação humana é garantir ao jovem e ao trabalhador adulto "[...] o direito a uma formaçáo completa para a leitura do mundo e para a atuação como cidadão pertencente a um país, integrado dignamente à sua sociedade política”. 


\section{Perspectivas de formação integrada nos cursos técnicos do IFMT, campus Rondonópolis}

Neste item apresentaremos de forma sucinta os resultados da pesquisa feita nos três cursos integrados desta instituição: Técnico em Alimentos Integrado ao Nível Médio, Técnico em Química Integrado ao Nível Médio e o curso Técnico em Secretariado Integrado ao Nível Médio.

A fim de compreendermos de que forma está sendo desenvolvida a formação integrada nestes cursos, foram analisados documentos que normatizam os referidos cursos, tais como o Plano de Desenvolvimento Institucional, a Organização Didática, Planos Políticos Pedagógicos dos Cursos, leis, diretrizes e resoluçóes.

Sob este aspecto Ciavatta (2012, p. 102) afirma que o horizonte de implementação e construção da formação integrada que almejamos está “[...] na sociedade, na adesão ou recusa de escolas, gestores, professores e alunos (com suas famílias) de avançar para a ruptura com todas as formas duais que permeiam a sociedade brasileira”.

Há de se considerar inicialmente que após a análise dos documentos legais que nortearam a criação dos Institutos Federais observou-se que eles possuem uma proposta de articulação com os setores produtivos principalmente no que se refere à geração e adaptação de soluçôes técnicas e tecnológicas às demandas sociais e as peculiaridades regionais, bem como a oferta formativa em benefício aos arranjos produtivos locais articulados ao setor produtivo.

A expansão da Rede Federal está atrelada também ao discurso de que ela é fundamental para o desenvolvimento econômico do país. Há de se contestar essa ideia, pois se a natureza da educação estiver voltada para o desenvolvimento econômico, ela estará delineada pelos interesses do mercado, e não pela concretização de uma educação de qualidade para a formação do ser humano na totalidade.

Ao analisarmos os projetos pedagógicos dos cursos (PPC) no que se refere à matriz curricular, observamos que a integração, conforme as propostas da politecnia, fica a desejar, pois constatamos apenas uma justaposição de disciplinas.

À primeira vista, a união de áreas distintas ou afins do conhecimento nos leva a crer que a integração curricular poderia estar ocorrendo de fato, no entanto, não podemos ter uma visão simplista de integração ante as propostas de formação humana integral. 
Os cursos foram concebidos com a finalidade de "[...] formar profissionais de acordo com as tendências tecnológicas da regiáo e em consonância com as demandas dos setores produtivos do município" (PPC, 2015c, p. 7), bem como, atender às "[...] necessidades e particularidades do mercado de trabalho da regiáo" (p. 17), onde estes profissionais devem ter "competências humanas" e "habilidades", a fim de assessorarem setores e pessoas nas áreas de "gestão empresarial", entre outras.

A abordagem pedagógica baseada nas competências apresenta o risco de se fazer "[...] um recorte restrito do que deve ser ensinado, limitando-se à dimensão instrumental e, assim, empobrecendo e desagregando a formação" (RAMOS, 2002, p. 154).

Os cursos de Química e Secretariado tiveram seus PPCs reformulados segundo as exigências da Resolução CNE/CEB no 6/2012, que em seu art. 13, item V, indica a "[...] atualização permanente dos cursos e currículos, estruturados em ampla base de dados, pesquisas e outras fontes de informação pertinentes". A reestruturação deu-se com a finalidade de "[...] atender às necessidades cada vez mais exigentes do mercado de trabalho" (IFMT/PPC, 2015b, p. 5), podendo os egressos desse curso suprir “[...] as necessidades atuais do mercado de trabalho" (p.16).

Quanto aos PPCs reformulados observamos poucas mudanças em sua estrutura, em ambos a formação está vinculada às necessidades empresariais, em que os egressos desse curso deveráo ser dotados de competências e habilidades ante a um mercado de trabalho exigente.

Ao analisarmos a matriz curricular do curso de secretariado, nos deparamos com a matriz curricular antiga (2011-2015) na qual está explicitada a separação das disciplinas do "núcleo comum" e a de "formação profissional", contrariando toda a concepção de formação integrada. Em 2016 o PPC do curso foi reformulado. No novo documento não consta de forma explícita essa divisão, no entanto comparando as duas matrizes poucas mudanças foram feitas, as disciplinas em sua maioria continuaram as mesmas, porém sem a distinção entre núcleo comum e de formação profissional.

Podemos perceber que os cursos analisados foram estruturados sob a ótica do capital, visto que objetivam a formação de profissionais para atuarem no mercado de trabalho, contrapondo-se à ideia de uma educação integrada que tem por base a formação para o mundo do trabalho. 
Em sentido completamente oposto à proposta do Ensino Médio Integrado nos deparamos com a contrarreforma do Ensino Médio empreendida pela Lei $n^{\circ} 13.417 / 2017$, contrarreforma esta que ataca os direitos da classe trabalhadora, tendo em vista que retoma os dispositivos de dualidade e fragmentação de reformas anteriores, atingindo de forma colossal o projeto de formação dos sujeitos na perspectiva da omnilateralidade.

\section{Considerações Finais}

A educação profissional integrada ao ensino médio, na ótica da politecnia, tendo como base a escola unitária em que o currículo possa ser articulado entre o trabalho, a ciência, a tecnologia e a cultura, passa a ser uma possibilidade de formação mais completa para os filhos da classe trabalhadora.

A educação vista na perspectiva da adaptabilidade e a formação dos profissionais técnicos desenvolvida de forma unilateral e não omnilateral nos remetem aos cursos criados sob a ótica do Decreto n. 2.208/1997. Os cursos criados nesse período eram alinhados ao mundo produtivo, com o objetivo de satisfazer os interesses do mercado, visavam apenas a formação laboral não permitindo uma formação humana integral.

É importante lembrar que o Plano Nacional de Educação ressalta que a oferta da educação profissional de qualidade faz-se urgente, no entanto, para garantir essa qualidade essa oferta tem de ser feita baseada nos princípios e compreensão de educação "unitária e universal", com superaçáo da dualidade entre "[...] as culturas geral e técnica, garantindo o domínio dos conhecimentos científicos referentes às diferentes técnicas que caracterizam o processo do trabalho produtivo na atualidade, e não apenas a formaçáo profissional stricto sensu" (BRASIL, 2014, p. 39).

Observamos que nos documentos há ambiguidades e contradiçóes a respeito da concepção de formação. Podemos situar duas grandes concepçóes que polarizam as concepçóes, nos documentos analisados: uma concepçáo de formação que se situa naquela demandada pelo mercado de trabalho, que podemos denominar de concepção neoliberal de educação profissional integrada e de currículo integrado, e a concepção que tentamos defender em nossa pesquisa, a concepção politécnica de educação profissional integrada e de currículo integrado objetivando a formaçáo humana integral. 
Essa segunda concepção aparece com força nos princípios, objetivos e metas do PDI e dos PPCs, mas não é "traduzida" para as matrizes curriculares, ou seja, a concepção politécnica que aparece nas grandes linhas norteadoras se perde quando analisamos as matrizes curriculares e as ementas das disciplinas. Assim, inviabiliza-se a possibilidade de concretização nas atividades disciplinares e técnicas, da formação omnilateral pretendida.

Que futuro se pode esperar da educação quando o Estado não apresenta políticas públicas consistentes para o setor, ainda mais quando somos surpreendidos por políticas de desmonte e sucateamento da educação. Prova disso é o ataque que estamos presenciando no cenário atual em nosso país com a contrarreforma educacional do Ensino Médio, empreendida pela Lei $n^{\circ} 13.417 / 2017$. Esta contrarreforma nos remete às políticas educacionais da década de 1990, quando a educação profissional pública, principalmente na Rede Federal, sofreu retrocessos e precarizaçóes devido ao alinhamento às políticas econômicas neoliberais e as orientaçôes dos organismos financeiros internacionais

O projeto de Ensino Médio Integrado da Rede Federal tendo o trabalho como princípio educativo, apesar das contradiçôes, é uma possibilidade da formação humana plena, no entanto, para que esse projeto se consolide, serão necessárias lutas nos planos ideológicos, políticos e econômicos.

\section{REFERÊNCIAS}

BRASIL. Decreto 2.208, de 14 de abril de 1997. Regulamenta o $\$ 2^{\circ}$ do art. 36 e os arts. 39 a 42 da Lei no 9.394, de 20 de dezembro de 1996, que estabelece as Diretrizes e Bases da Educação Nacional. Diário Oficial da Uniáo, Brasília, 18 abr. 1997.

. Decreto n. $5.154 / 04$ - Regulamenta o $\$ 2^{\circ}$ do art. 36 e os arts. 39 a 41 da Lei ${ }^{\circ}$ 9.394, de 20 de dezembro de 1996, que estabelece as diretrizes e bases da educação nacional e dá outras providências. Diário Oficial da Uniáo, Brasília, 24 jul. 2004.

. Lei no 9.394, de 20 de dezembro de 1996. Estabelece as diretrizes e bases da educaçáo nacional. Diário Oficial da Uniáo, Brasília, 23 dez. 1996.

. Ministério da Educação. Conselho Nacional de Educação. Resoluçáo CNE/CEB $\mathbf{n}^{\circ}$ 6/2012. Define Diretrizes Curriculares Nacionais para a Educaçâo Profissional Técnica de Nível Médio. Brasília, DF, 2012.

. Planejando a próxima década: conhecendo as 20 metas do Plano Nacional de Educação. Brasília: Ministério da Educação, 2014. 
FRIGOTTO, Gaudêncio; CIAVATTA, Maria. Educar o trabalhador cidadáo produtivo ou o ser humano emancipado. Trabalho, Educação e Saúde, v. 1, n. 1, p. 45-60, 2003.

FRIGOTTO, G., CIAVATTA, M.; RAMOS, M. O trabalho como princípio educativo no projeto de educação integral de trabalhadores. In: COSTA, H.; CONCEIÇÃO, M. (Org.). Educaçáo integral e sistema de reconhecimento e certificaçáo educacional e profissional. São Paulo: Cut, 2005a . p. 19-62.

Introdução. In: FRIGOTTO, Gaudêncio; CIAVATTA, Maria; RAMOS, Marise (Orgs.). Ensino médio integrado: concepçóes e contradiçóes. 3. ed. São Paulo: Cortez, 2012b.

GARCIA, Nilson Marcos Dias; LIMA FILHO, Domingos Leite. Politecnia ou educação tecnológica: desafios ao ensino médio e à educação profissional. Reunião anual da ANPED, v. $27,2004$.

GRAMSCI, Antonio. Os intelectuais e a organização da cultura. Tradução de Carlos Nelson Coutinho. 4. ed. Rio de Janeiro: Civilização Brasileira, 1982.

INSTITUTO FEDERAL DE EDUCAÇÃO, CIÊNCIA E TECNOLOGIA DO MATO GROSSO (IFMT). Plano de Desenvolvimento Institucional (2014/2018). Disponível em: http://ifmt.edu.br/media/filer_public/b3/cb/b3cbb909-bb6d-48c7-abe8-d723d23dacc7/ pdi-oficial-consup-ultima-versao1.pdf. Acesso em: 14 jul. 2017.

Projeto pedagógico do curso Técnico em Alimentos Integrado ao Nível Médio do campus Rondonópolis. 2015a. Disponível em: http://roo.ifmt.edu.br/media/ filer_public/5c/60/5c602343-0c27-44b1-a9f81465e9ca0eef/2016_ppc_tecnico_em_alimentos_integrado_ao_nivel_medio_-_versao_oficial 1.pdf. Acesso em: 10 abr. 2017.

. Projeto pedagógico do curso Técnico em Química Integrado ao Nível Médio do campus Rondonópolis. 2015b. Disponível em: http://roo.ifmt.edu.br/media/filer_public/ d4/87/d4877af8-da9a-4506-9bc3-a05dac30e0cc/ppc_curso_tecnico_em_quimica_integrado_ao_nivel_medio_reestruturado_05122016-2.pdf. Acesso em: 10 abr. 2017.

Projeto pedagógico do curso Técnico em Secretariado Integrado ao Nível Médio do campus Rondonópolis. 2015c. Disponível em: http://roo.ifmt.edu.br/media/filer_public/53/ e7/53e78ecd-32d7-42d9-942d 7bd2cb845523/2016_ppc_tecnico_em_secretariado_integrado_ ao_nivel_medio__versao_oficial.pdf. Acesso em: 10 abr. 2017.

KUENZER, Acácia (Org.). Ensino médio: construindo uma proposta para os que vivem do trabalho. 5. ed. S. Paulo: Cortez, 2007.

MANACORDA, Mario Alighiero. Marx e a pedagogia moderna. Campinas, SP: Alínea, 2007.

O princípio educativo em Gramsci: americanismo e conformismo. 2. ed. Campinas, SP: Editora Alínea, 2013.

MARX, Karl; ENGELS, Friedrich. Textos sobre educação e ensino. Campinas, SP: Navegando, 2011. 
MONASTA, Attilio. Antonio Gramsci. Tradução: Paolo Nosella. Recife, PB: Fundação Joaquim Nabuco, Editora Massangana, 2010.

MOURA, Dante Henrique. Mudanças na sociedade brasileira dos anos 2000 limitadas pela hegemonia do neoliberalismo: implicaçóes para o trabalho e para a educação. In: MOURA, Dante Henrique (Org.). Produção de conhecimento, políticas públicas e formaçáo docente em educaçáo profissional. 1. ed. Campinas, SP: Mercado de Letras, 2013b.

Ensino médio integrado: subsunção aos interesses do capital ou travessia para a formaçáo humana integral? Educaçáo e Pesquisa, v. 39, n. 3, 2013c.

NOSELLA, Paolo; AZEVEDO, Mário Luiz Neves. A educação em Gramsci. Teoria e Prática da Educaçáa, v. 15, n. 2, p. 25-33, 2012.

PIRES, M. F. C. O materialismo histórico-dialético e a educação. Interface - Comunicação, Saúde, Educaçáo, v.1, n.1, 1997.

RAMOS, Marise Nogueira. Pedagogia das competências: autonomia ou adaptação? São Paulo: Cortez, 2002.

SAVIANI, Dermeval. Sobre a concepçáo de politecnia. Rio de Janeiro: FIOCRUZ. Politécnico da Saúde Joaquim Venâncio, 1989. 